\title{
A THEORICAL POINT OF VIEW OF REALITY, PERCEPTION AND LANGUAGE
}

\author{
J. Nescolarde-Selva, J.L. Usó-Doménech \\ Department of Applied Mathematics.University of Alicante. Alicante. Spain.
}

H. Gash

Education Department. Dublin City University. Dublin. Ireland

\begin{abstract}
It is possible to view the relations between mathematics and natural language from different aspects. This relation between mathematics and language is not based on just one aspect. In this paper the authors address the role of the Subject facing reality through language. Perception is defined and a mathematical theory of the perceptual field proposed. The distinction between purely expressive language and purely informative language is considered false, because the subject is expressed in the communication of a message, and conversely, in purely expressive language, as in an exclamation, there is some information. To study the relation between language and reality, the function of ostensibility is defined and propositions are divided into ostensives and estimatives.
\end{abstract}

Keywords: Communication, Estimative function, Ostensive function, Perception field

\section{INTRODUCTION}

Language is in the origin of the conception of Reality. But, what Reality we are talking about? LeShan and Margenau (1982) propose that the organization of knowledge divides Reality in domains of experience and in each one of them certain observable phenomena are expressed. Some domains have a direct relation with each other and when this happens it is possible to make a series of formulations defined by their relations. When the domains are interrelated according to scales of dimensions of complexity usually we can say that they form a hierarchy. In these conditions, the observable phenomena in one domain cannot be conceived nor be predicted generally from another domain. But if two domains are considered to be in opposed directions, we can verify that the observable phenomena in the second domain can be explained taking care of the phenomena of the first domain. According to these authors, an important general law concerning domains is as follows: the observable phenomena that appear in any domain legitimately are interrelated .In accordance with the present state of knowledge and science, no domain of experience is more real than another one. Each one has the same worth as another one. "Nature has neither rind nor bone", said Goethe. We chose a domain according to our purposes. Even though the domains are related in a hierarchy none of them is more real than the other. The domains enter groupings called spheres and each sphere has one special organization of Reality (its Metaphysical system) that is necessary so that the data of that sphere are valid. LeShan and Margenau define five spheres of experience:

a) Sphere of things too small to be seen or touched at least theoretically: the Microcosm. It is the field of Quantum Mechanics.

b) Sphere of the tactile line of vision and up to the limits of instrumentation. It could be called also the sensory sphere or average existence. 
c) Sphere of very large objects or things that theoretically happen too fast to be seen or to be touched: Macrocosms. It is the field of relativistic Physics.

d) Units of conduct with sensory feedback: conduct units that depend on reflections.

e) Sphere of inner human experience, including bodily sensations.

In this work the authors address the role of the Subject facing reality through language. The distinction between purely expressive language and purely informative language is considered false, because the subject is expressed in the communication of a message, and conversely, in purely expressive language, as in an exclamation, there is some information. To study the relation between language and reality, the function of ostensibility is defined and propositions are divided into ostensives and estimatives.

\section{BACKGROUND: REALITY AND FORMAL LANGUAGES}

Referring to formal languages, mathematicians seem reluctant to refer to the " concepts existing behind the symbols" as meaningless, or to claim that mathematical entities are non-existent, and this reluctance is sufficiently justified because of the pejorative nature of such terminology. The ontological status of mathematical entities, such as matters of paradox, haves a long history of philosophical debates, perhaps because of their close relationship to the problem of universals.

Language may be defined like a symbolic substitute of Reality, or as a system of signs. Different classes of objects exist, that they-are characterized by different mental acts through which we perceive them from its surroundings (Meinong, 1904). Objects of sensorial perception are different from objects of thought, but these last ones are not less "objective" than the previous ones: they are apprehended through thought but it does not constitute them. According to the terminology of Meinong, meaning subsists, whereas individual beings and qualities exist. In this sense, objects of thought can be real without existing in the technical sense defined by Meinong. Mathematical objects are of this class. The first condition is (Agazzi, 1992) that these objects are there, and this is not made through an act of discourse, but through the presence of these objects in the Subject's thought. The phenomenological situation may be that an object, simply by the fact of being present, offers to the Subject an irrefutable witness to itself. The referential situation is one of phenomenological presence of the object. The truth of a sentence is the coincidence with the situation of its phenomenological presence. It is to notice that meanings or understandings are only partially faithful with respect to any particular phenomenological presence or referential situation that they could denote. Some form of modalization (alethical, deontical or doxical) necessarily accompanies the communication. Thought and language are epistemologically separate. Language organization depends on a complex structure. Biunivocal correspondence between the perception of Reality and the linguistic system is unthinkable. Perception of reality operates from a superior order, from a mesosystem that would include both, and in which each appear like elements and not like closed and independent units. The horizontal forces of any system are those that determine their potential of significance. This means that no language is neutral. That is to say, the systemic conception, like any 
other semiotic conception, represents the-Reality in the same way as other non systemic conceptions.

The mind of the Subject, belonging to a particular society forms a conceptual space of representation (CSR) of Reality that includes in principle, three subspaces:

a) Conceptual Subspace of the immediate reality.

b) Conceptual Subspace of representation of the mediate reality

c) Conceptual subspace of representation of the distant reality.

In CSR represents the "natural" reality, is to say, the material and energetic transactions, like the physical base and its structural base (Usó-Doménech and Nescolarde-Selva, 2012). In addition the CSR is directly perceivable to thought, or, more directly, can have representation in private language. But the fundamental thing is that the effectiveness of a language depends mainly, on the existence of a displaced plane, in which as much the language as the represented thing exert a mutual tension that can be represented in a tense and reticular geometry ${ }^{1}$. We see then that the objective of reaching an understanding of reality by mediation of mental or linguistic models could never totally be reached. It means that the linguistic model produces acceptable responses, but not inadmissible responses to experienced aspects of reality. That is to say, acceptable responses arise from the model, but not inadmissible responses.

Language is relative as well. How can we speak about absolute being, then? We can and we cannot. But that we cannot completely speak about it, it is not a reason to stop speaking about it (Wittgenstein, 1972), because we can incompletely represent its completeness. Language is used inside a context. Depending of this context language will be different. We would not be able to speak about anything if we thought we were completely representing reality because languages are incomplete.

A symbolic system is any system governed by the distinction between the significant and significance (Usó-Doménech and Nescolarde-Selva, 2012; Nescolarde-Selva and Usó-Doménech, $2013^{\mathrm{a} \cdot \mathrm{b}}$ ), a distinction that, although it is specific to the linguistic field, implies in addition:

a) A sense perception never arises at the level of an isolated term, but of a structured chain where the diverse composing elements is more important that the particular nature of these elements.

b) Any modification in some of these elements affects all the chain, and the significance always finds a multiplicity of expressions that, latent or present, define the framework within which any progress in the evolution of all the significances is developed.

All efforts to make correspond, term upon term, significant and significance is devoid of sense: it implies that the significant totally preexists to the represented object, because

\footnotetext{
${ }^{1}$ Reticular geometry is an area of geometry concerned with large and complex geometric objects consisting of many articulating components.
} 
the language is a set of correlations between certain words and diverse conceptual contents, the same number of objects totally determine these contents. However, the differentiated units to which the concepts are applied and the significance of these concepts is not the reflection of the word that carries them and do not form reality. This contingency of the relation between the two faces of the sign springs from the nature of human communication, more exactly from the structure of all semiotic system. This is simultaneously a unitary structure of two heterogeneous levels of the reality where are objects and the differential definition of these objects that only carry information.

The interaction between nature and culture comes from a humanization of natural reality. Nature becomes culture, not in regard to an equivalence ratio, but by integration of a certain number of natural elements to a type of order that characterizes the culture. This characteristic is a characteristic of all symbolic systems and all discourses, when the message contains an additional codification to the personal codes of the language. This implies the use of information taken from a sphere different from the sphere in where the system works, information that can be physical (colors, sounds, sensations, gestures, etc.) or cultural (provided by already existing the semiotic systems) in an application that is ordered by virtue of an organization principle. The abuse of a sign, resulting from the association of two different spheres from reality, is reinforced by the integration of each significant unit in a differentiated system that is unique, allowing the appearance of the semantic sense-like effect. The significance is never directly attainable but it is indirectly available through instrumental material that is been taken from another sphere of reality. Significance is the best we can do in terms of understanding the significant in a particular and isolated way, nothing else it can reach it. In language, this refraction process is double:

1) At first, it corresponds to the constitution of this same information, that is to say, the laws that all images must obey for being significant. This process designates the type of culturization of nature.

2) In the second phase, it corresponds to the relation that each one of these significant units maintains with other units, and this relation is the unique way of defining significances accurately. This process is the elaboration of reality operating through the interrelation of these significant units.

Morowitz (2012) argues that one can only talk about one ontology if we are to assume that there is only one reality. But there is one Reality? For Nescolarde-Selva and UsóDoménech $\left(2013^{\mathrm{b}}\right)$ the essence of the organization of Reality is that the data of each sphere of experience must be taken on its own terms without preconceptions. What can differ in each sphere of experience are not only observables and their relations, not only the definitions of space, time, state and observer, but also the methods to study for each domain. Therefore, the sender (observer) is located, without being aware of it, in fragmented and divided Realities.

Gershenson and Fernández (2012) use information theory to provide abstract and concise measures of complexity, emergence, self-organization, and homeostasis. In this paper the authors clarify the meaning of these concepts with the aid of the proposed formal measures. 
Each society structuring a different systemic world view orders its relation to its own instruments of thought self distributing the use of space and the temporary extension of its own existence. It is necessary to ask about the relationship between the sender and the signs used, how knowledge of cause is created (case of axiomatic systems), how learning happens (language) without the sender dominating these operations (dream).We show that reference to the intention of the Subject that conceives is insufficient to account for everything that is produced, because this being that is produced has its existence in relation to other elements of a system, within which all creation operates and, except in formal logical or mathematical systems, it never has the equivalent of total subjectivity. Each semiotic system is nourished in a particular domain - that comprises a natural or cultural world- and the selection of this material is constrictive, because it partially determines the type of syntax that will be applied and the concepts used. Thus, each system, more or less complex, will be observed by the Subject from a plurality of angles.

By virtue of this discussion we propose the following principle:

Principle of Semiotic Incompleteness (Usó-Doménech and Nescolarde-Selva, 2012; Nescolarde-Selva and Usó-Doménech, 2013.b): It is not possible to totally characterize a structure of objects or processes, through a language (formal or not), or to completely present a portion of "truth" that this language can express on these objects or processes through its deductive operation.

\section{THE PERCEPTUAL FIELD}

Gershenson (2001) defines two types of being: absolute being and relative being. The first one is independent of subject $S$ and infinite. Relative being is dependent on the Subject, therefore finite, and different in each individual. Absolute being is far from materialism and we cannot understand it completely. Materialism is known from individual points of view and relative, and we cannot say for sure what absolute beings are, because we do not know absolute matter. A Subject can only speculate or suppose about the things that are absolute, he cannot be absolutely sure, he can only use concepts, because absolute beings are infinite and a Subject is not. A Subject cannot say that something in his experience is absolutely true or false. He can only assert beings in a relative way and he could assign truth values or vectors to them, but these would be relative to his context. The being we know would be the conjunction of relative beings we know and absolute being is unknowable, with the corresponding confusion derived from the fact that to define and to speak about something that is absolute and infinite is impossible, whereas we can talk about what is relative and finite. This is what we do every day. Beings do not have an intrinsic meaning and they only transform themselves into signs when we invested them with meaning.

Let $\mathrm{S}$ be a subject, and $\mathrm{O}$ an object under specified conditions. Maddy's conditions (Maddy, 1990, 1996; Usó-Doménech and Nescolarde-Selva, 2012; Nescolarde-Selva and Usó-Doménech, $2013^{\text {a.b }}$ ) for physical perceptions are as follows:

The $\mathrm{S}$ perceives $\mathrm{O}$ if:

1) There is O. It is the absolute being, referent or designatum.

2) S has perceptual beliefs pB about $\mathrm{O}$, in terms of the appropriate sort of concepts. Rather than talking about a physical object belief, one talks about the concept of 
a physical object, relative being or designata. This is based on the assumption that having a concept of a physical object entails that one has physical object beliefs.

3) O causes S's beliefs B about O.

Definition 1: To significances, that are consequence of perceptual beliefs $p B$ on the part of a Subject $S$ of an object $O$ with certain characteristic $C$, we call perceptual significances (p-significance) and we denote as ps.

Let ps be a perceptual significance, $\mathrm{pB}$ be a set of perceptual significances such that $p B=\left\{p s_{1}, p s_{2}, \ldots ., p s_{n}\right\}, \wedge$ be an operation meaning "subject $\mathrm{S}$ and perceives $\mathrm{O}$ " (perceptual conjunction), $\vee$ be an operation meaning "subject $S$ or perceives $O$ " (perceptual disjunction).

Definition 2: A perceptual field is a set $p B$ that is a commutative group with respect to two compatible operations, $\wedge$ and $\vee$, with "compatible" being formalized by distributivity, and the caveat that the $\wedge$ identity $\left(\mathrm{ps}_{0}\right)$ has no $\vee$ inverse.

Perceptual fields have the following properties:

1) Closure of $p B$ under perceptual conjunction and perceptual disjunction. $\forall p s_{1}, p s_{2} \in p B ; \quad p s_{1} \wedge p s_{2}, p s_{1} \vee p s_{2} \in p B$

2) Associativity of perceptual conjunction and perceptual disjunction. $\forall p s_{1}, p s_{2}, p s_{3} \in p B ; \Rightarrow p s_{1} \wedge\left(p s_{2} \wedge p s_{3}\right)=\left(p s_{1} \wedge p s_{2}\right) \wedge p s_{3}$ and $p s_{1} \vee\left(p s_{2} \vee p s_{3}\right)=\left(p s_{1} \vee p s_{2}\right) \vee p s_{3}$

3) Commutativity of perceptual conjunction and perceptual disjunction. $\forall p s_{1}, p s_{2} \in p B ; \Rightarrow p s_{1} \wedge p s_{2}=p s_{2} \wedge p s_{1}$ and $p s_{1} \vee p s_{2}=p s_{2} \vee p s_{1}$

4) Existence of perceptual conjunction and perceptual disjunction identity elements There exists an element of $p B$, called the perceptual conjunction identity element and denoted by $p s_{0}$, such that $\forall p s_{i} \in p B ; \quad p s_{i} \wedge p s_{0}=p s_{i}$. Likewise, there is an element, called the perceptual disjunction identity element and denoted by $p s_{\aleph}$, such that $\forall p s_{i} \in p B ; \quad p s_{i} \vee p s_{\aleph}=p s_{\aleph}$.

5) Existence of perceptual conjunction inverses and perceptual disjunction inverses $\forall p s_{i} \in p B ; \quad \exists \neg p s_{i} / p s_{i} \wedge \neg p s_{i}=p s_{0}$

Similarly, for any a in $F$ other than 0 , there exists an element $a^{-1}$ in $F$, such that $a \cdot a^{-1}=1 . \forall p s_{i} \in p B ; \quad \exists\left(p s_{i}\right)^{-1} / p s_{i} \wedge_{i}\left(p s_{i}\right)^{-1}=p s_{\aleph}$

6) Distributivity of perceptual disjunction perceptual conjunction $\forall p s_{1}, p s_{2}, p s_{3} \in p B ; \Rightarrow p s_{1} \vee\left(p s_{2} \wedge p s_{3}\right)=\left(p s_{1} \vee p s_{2}\right) \wedge\left(p s_{1} \vee p s_{3}\right)$ 
Definition 3: A perceptual field is therefore an algebraic structure $\left\langle p B, \wedge, \vee, \neg,{ }^{-1}, p s_{0}, p s_{\aleph}\right\rangle$, consisting of two abelian groups:

1) $p B$ under $\wedge, \neg$, and $p s_{0}$;

2) $p B \backslash\left\{p s_{0}\right\}$ under $\vee,^{-1}$, and $p s_{\aleph}$, with $p s_{0} \neq p s_{\aleph}$, with $\cdot$ distributing over $\wedge$

Note 1: $\wedge$ perceptual conjunction identity element $\left(\mathrm{ps}_{0}\right)$ means no perception of any object.

Note 2: $\vee$ perceptual disjunction identity element $\left(p s_{\aleph}\right)$ means perception of all objects including "silence" or "blanks".

Note 3: $\neg p s_{i}$ means no perception of the object whose perceptual significance is $p s_{i}$

Note 4: $\left(p s_{i}\right)^{-1}$ means perception the complementary to $p s_{i}$ and "silences" or "blanks"

We should ask ourselves how subject S, located before a perceptual field in which there are innumerable perceptual significances $\mathrm{ps}_{1}$, to highlight precisely one and leave us perceive others. How is this possible, that the circumvented objects $\mathrm{O}_{\mathrm{i}}$ have also been perceived, if they do not lack quantitatively ostensible traits to justify no perception? It is a function of the perceiving subject. The unperceived (Freud, 2010) is a significant. In other words what is not perceived is also a component of what is experienced, which can be placed in the heart of a polisyntagmatic chain that makes up the total discourse. That perception implies, in the logical sense of the word, what has ceased being noticed and somehow is discovered in what has been experienced ${ }^{2}$.

By group theory, applied to the abelian groups $\left(p B^{\times}, \vee\right)$, and $(p B, \wedge)$, the perceptual conjunction inverse $\neg p s_{i}$ and the perceptual disjunction inverse $\left(p s_{i}\right)^{-1}$ are uniquely determined by $p s_{i}$.

Similar direct consequences from the perceptual field axioms include $\neg\left(p s_{1} \vee p s_{2}\right)=\left(\neg p s_{1}\right) \vee p s_{2}=p s_{1} \vee\left(\neg p s_{2}\right)$, in particular $\neg p s_{i}=\left(\neg p s_{\aleph}\right)$ as well as $p s_{i} \vee p s_{0}=p s_{9}$.

\section{LANGUAGE AND SUBJECT}

Language is primarily an expression or projection of the sender. The message and expression are interlinked which means that language and information are also intertwined even in those cases where the message is given no ostensible subject, as in the case of a CD. The distinction between purely expressive language and purely informative language is false, because the subject is expressed in the communication of a message, and conversely, in purely expressive language, as in an exclamation, there is some information. All this is visible when language as a system becomes speech, which

\footnotetext{
${ }^{2}$ It is curious to note that in certain schools of Jewish mysticism (Abraham Abulafia), blank spaces of Torah signify letters that are more important than real black letters written in the text. For these schools, there is a hidden Torah in these blanks between the black letters; the interpretation is that this as where each human being has to write in his own existence (Sabán, 2012).
} 
is actually a specific form of language; from which all other forms emerge. Even when use is made of ad hoc language, as is the case of scientific languages, one can recognize transcripts of speech, because they refer to a reality, albeit purely abstract, as in logical syntax or the language of theoretical physics. Also formalized languages always contain expressive component, so that the sender is more or less notoriously visible. To say "more or less notoriously" is to state the following:

1) The constancy of the sender as the origin of the proposition.

2) That being less notoriously in certain forms of language only denotes that the receiver requires more hermeneutic effort.

Definition 4 (Russell, 1984): Ostensive definition is the process by which an individual receives instruction to understand a lexeme in a different way than through the use of other lexemes

We can therefore formulate the following law we will call the Law of ostensibility.

Law of ostensibility: The ostensibility of a sender is in inverse proportion to the quantity of information being provided by a particular language.

The jargon of a mathematician seems to say little about the subject that uses it. But it would still be susceptible of analysis under ideological considerations, and this refers to the objective and subjective conditions of the sender. Morris (1946) was forced to recognize the expressive character of language even in the use of simple scientific propositions, stating "If a person often uses the language of physics, this may be an indication of their interest in certain things before others". Consider the following example:

Example 1: Here is a paragraph from Henry James:

The gondola stopped, the old palace was there; it was a house of the class which in Venice carries even in extreme dilapidation the dignified name. "How charming! It's gray and pink!" my companion exclaimed; and that is the most comprehensive description of it. It was not particularly old, only two or three centuries; and it had an air not so much of decay as of quiet discouragement, as if it had rather missed its career. But its wide front, with a stone balcony from end to end of the piano nobile or most important floor, was architectural enough, with the aid of various pilasters and arches; and the stucco with which in the intervals it had long ago been endued was rosy in the April afternoon.(The Aspern Papers).

In a sense, it seems that this piece of Henry James is like a documentary scene. James's vision about a certain reality is created so that the reader (receiver) is supplied much more easily given the deception of the author's hypostasize. One wonders after reading: Is this all reality? Is it even more essential reality? Does it not involve the information of reality lived by him, his situation to reality as a whole, apprehending a parcel to circumvent the remaining? Does the nature of the message itself not reside in its presence, and its subsequent absence? We can recognize two things: 
a) Adoption of aloofness, the substantive, with a limited use of adjectives, is indicative of the extent James adopts an expectant attitude to reality, as if he rejects any affective immersion in it.

b) The reality that the author apprehends (and that he ignores), despite his distancing, it's just of the thing, and in addition to certain things, so that, by their selection and rejection, James speaks for himself without effort.

This leads us to conclude that language can be seen as a chain of double significants (Usó-Doménech and Nescolarde-Selva, 2012; Nescolarde-Selva and Usó-Doménech, $2013^{\text {a.b }}$ ) where the silence is also a significant.

Just before this objectivist paragraph, here's another in which the author manifests his presence in what he describes, as if place himself into the character he describes.

Example 2: We will now present a paragraph of Memoirs of Fanny Hill by John Cleland

Imagine to yourself, a man rather past threescore, short and ill-made, with a yellow cadaverous hue, great goggle eyes, that stared as if he was strangled; an out-mouth from two more properly tusks than teeth, livid lips, and breath like a Jake's: then he had a peculiar ghastliness in his grin, that made him perfectly frightful, if not dangerous to women with child; yet, made as he was thus in mock of man, he was so blind to his own staring deformities, as to think himself born to please, and that no woman could see him with impunity: in consequence of which idea, he had lavished great sums on such wretches as could gain upon themselves to pretend love to his person, whilst to those who had not art or patience to dissemble the horror it inspired, he behaved even brutally. Impotence, more than necessity, made him seek in variety, the provocative that was wanting to raise him to the pitch of enjoyment, which he too often saw himself baulked of, by the failure of his powers: and this always threw him into a fit of rage, which he wreaked, as far as he durst, on the innocent objects of his fit of momentary desire.

In these lines Cleland highlights his inability to distance himself from reality. The value judgments in the words, the effects described in the text, and so on, do not connote but denote directly, brutally, the author's own axiology. In short, not too much interpretive effort is required to learn about Cleland, less effort than required to learn about the person described.

It should be clear that in these passages both James and Cleland, use predicates extensively. And secondly, insofar that, in addition to expressing, and reporting, they describe objects (people, things) using predicates. Therefore:

Hypothesis 1: Every language is a double proposition subject-predicate:

a) The subject of the proposition, depends on the expression of the sender.

b) Of the subject of the sentence is given apparent objectivity by the sender despite its subjectivity. 
All language is meaningful provided it is optional and this optional character is twofold:

1) What to talk about is optional.

2) How to talk is optional.

\section{SENTENCES AND PROPOSITIONS}

The linguistic act should be studied considering the relationship between sender and receiver within a context. That is, the linguistic act is to gather sender and receiver, speaker and listener, and place both in a real context, outside of which, the language would, in fact, uninterpretable (De Ajuriaguerra et al., 1963). The locutional and transformational grammars, explain the grammatical and surface structure of the sentence by generating structures, and seek to explain, ultimately, the link between language, as something given in the form of speech, and the logical syntax of thought (which does not have to match the logicality of the sentence). For this reason one must ask: how is that we can understand a poorly constructed or deficient sentence? In reality, this is only successful insofar as the sender and receiver know the optional nature of the language,the character referred to in the situation, the object of the message and even then the possibility of misinterpretation is clearly present. Only attention to context, one of whose constituents is the receiver (Lepschy, 1964), makes it possible to give meaningful character to sentences with low grammaticality, to periphrastic constructions, even to silence, which has been relatively unnoticed by linguists. The possibilities of understanding (or misunderstanding) above and beyond what is superficially expressed, is what has made possible the enormous richness of literary expression,and of colloquial language. Such varieties of interpretation or nuances of meaning are due to the significance of what is hidden, because first interpretations favor what is most evident and externalized. All this is because speech "is the actual form of consciousness." (Marx, 1998).

Grammar may be used to analyse a speaker's language independently of its expressive function, using adjectives adverbs and interjections. This means that there can be a contradiction because the same grammar can be used in an analysis of a set of sentences or of a set of propositions, proposed by a sender. However, two identical sentences with the same words may be different as propositions.

Example 3: Is already well Enough!!

Is already well $\equiv$ do not need more, let's leave now.

Only when the subject of the sentence and the proposition coincide in the same explicit person is one obliged to refer to peculiarities which in any case concern the psychology of the sender.

Example 4: Let us consider the sentence: Sarah is in the garden.

A grammarian can ignore the implicit subject of this proposition - that is, one that issues - to materialize, as the object, in the subject of the sentence, in this case "Sarah". But in the next sentence: I say Sarah is in the garden we find that there is a subject of the proposition, it's me, a subject of the sentence "I say" and a coordinated subject of the sentence, "Sarah". 
To give a general definition of a proposition we will use a simplified procedure from Tarski (1956). First, there is a distinction between primitive and compound propositions. A primitive proposition is a combination of an individual expression such as "Alhambra" and a predicate such as "being in Granada"; there are also primitive propositions made up of several individual expressions and predicates. A compound proposition is formed from one or more primitive propositions, properly adding "no", "or", "and", "if", "then", "all", "at least one" and other connectives.

Grammar in the classical sense is only obliged to refer to psychological categorizations in cases where the subject of the proposition is explicit. In tree diagrams (stegmas) this becomes clearer (Figure 1). Let $\mathbf{P}$ be a proposition, EG be the external to the sentence group (elided), SG be the sentential group, NG be the nominal group and VG be the verbal group.

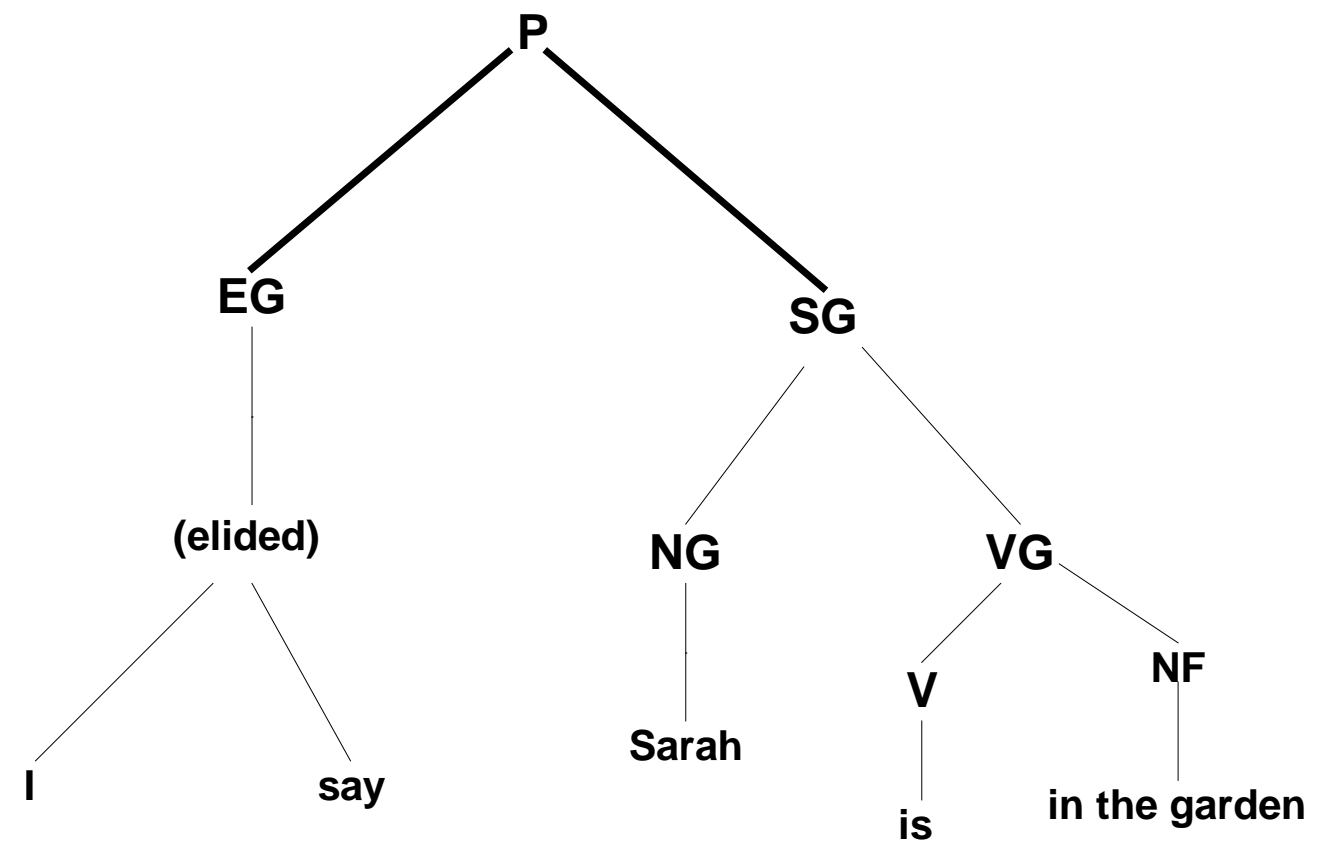

Figure 1: Tree diagram of example 4.

But it is evident that sentences are always propositions, i.e., proposals of a sender, and do not appear ex nihilo. The consistency of grammar is tested where it is forced to surreptitiously estimate the sender's meaning (Schaff, 1962). And must be said that traditional grammar is responsible for fallacies spawned in language use, which have been petrified and perpetuated. A particularly serious one in this regard is derived from the traditional concepts of predication and attribution. By failing consider the subject of the proposition, predicates and attributes are the subject of the sentence, which is true for predicates (ie verbal predicates), and false for attributes or nominal predicates.

Example 5: Suppose the sentence: Sarah is beautiful. It is inferred that beauty is the property of Sarah, when in any case it is a designation by the subject of the proposition, implicit in the subject of the sentence, Sarah. It is clear that while Sarah for the subject 
$\mathrm{X}$ can be beautiful, may not be beautiful for subject Y. In any case, these estimates cannot be verified or determined by a supposed referee.

It is estimated that although most of the time the predicate is an adjective, like the example above, other times it can be a noun, as in the sentence: Sarah is a teacher. But sometimes, a noun can be either an adjective, because the genetic moment, attributed by the subject of the proposition, is undeniable and ineludible. So in the sentence: Sarah is a woman, it is the tone that is emitted the proposition that decides the interpretation of the ambiguity that would result from considering "woman" as a noun (female subject) or as an adjective (a synonym of some sexist attribute).

The perpetuation of verbal fallacies (Russell, 1984) comes from the fact that grammar, by dispensing with the subject of the proposition, and attending exclusively to the sentence, has contributed to establishing two types of errors:

1) Attributes are properties of the subject of sentence, when in any case they are properties that are conferred by the subject of the proposition.

2) The existence of adjectives as attributable properties is inferred from the existence of nouns as entities.

Example 6: Given that A, B, C are beautiful it is inferred that beauty exists, but this has not been proven by anyone, even in the form of an ostensive definition.

All this is due to inadequate analysis that grammarians have made the verb "to be" excusable in those natural languages in which there is no differentiation with the "to stand" ${ }^{3}$. It is curious that verbal predicates as in:

a) Sarah walks.

b) The dog eats.

c) The tree falls.

They are grammatically considered as circumstantial when really they denote facts and are therefore substantives, however, the qualities like "beautiful", "good", "brave", appear as substantives of the subject of sentence and in any case exist outside the subject of the proposition to which they are associated.

\section{OSTENSIVE AND ESTIMATIVE FUNCTIONS}

There is no communication without the triple consideration of what is transmitted in the sense proposed by Bühler (2011):

a) Representation.

b) Expression or syntony of someone who transmits.

\footnotetext{
${ }^{3}$ In Spanish there is a difference between "I am" and "I stand". This distinction does not exist in Catalan. In Hebrew there is no present tense as it is reserved for God.
} 
c) Signal to the receiver.

We will outline three possibilities that language offers when it works as a communication medium between sender and receiver:

1) An ostensive definition conveys meaning using examples. In this case a Sender refers to an absolute being or referent (Ogden and Richards, 1989), also known as designatum (Carnap, 1942). In this case the information about the referent is in the foreground. The language in this situation is called an ostensive function $\left(O_{F}\right)$, because the proposition is the translation of an ostension, equivalent to a remark. When the Subject makes a proposition or set of ostensive propositions Subject is operating on Reality. We must remember that for the Subject reality is processed with a system of signs encoded in language. Both signs and language are heterologous systems or related ways of representing reality. This lack of congruence between the system of signs that make up the process of the real and the codified system of linguistic signs has the following implications:

a) The semiotic system used to represent reality is a continuous and evolving process, but the coding is discontinuous. This discontinuity requires the perceiving Subject to make an optional decision about which aspect of the process of representing Reality to verify.

b) In turn, the coding performed is optional.

c) There is one relationship between the systems of the verified coding and the processes of representing the real. In any case, this is like a kind of interpretation of a sector of reality by denotative significance.

Between Reality conceived as system (Nescolarde-Selva and Usó-Doménech, $2012^{b}$ ) and the linguistic coding system there is no identity (isology) or isomorphism, but at most, equivalence. In speaking about Reality, a Subject first selects from the perceptual field in a pragmatic way, and then transmits a message even at the expense of substantive categories.

2) Where a proposition does not refer to an observable absolute being what is communicated becomes a self evaluative expression. This function is called $a$ predicative function $\left(\mathrm{E}_{\mathrm{F}}\right)$ or self evaluative function.

Example 7: (You) look at this landscape is an example of ostensive function. I feel depressed is an example of estimative function.

Most often language is made up of mixed propositions in which both ostensive and estimative functions occur simultaneously or successively.

Example 8: Suppose the proposition $\mathbf{P}$ "This woman is attractive (to me) or I think this woman is attractive ". $\mathrm{O}_{\mathrm{F}}$ is determined by the first member of the proposition (This woman) and $\mathrm{E}_{\mathrm{F}}$ by the second member (I feel she is attractive). In fact, there are two propositions, given unitary, but the receiver is forced to separate, to attend to the ostension contained immediately before the ulterior estimate. In a tree diagram we will have (Figure 2): 


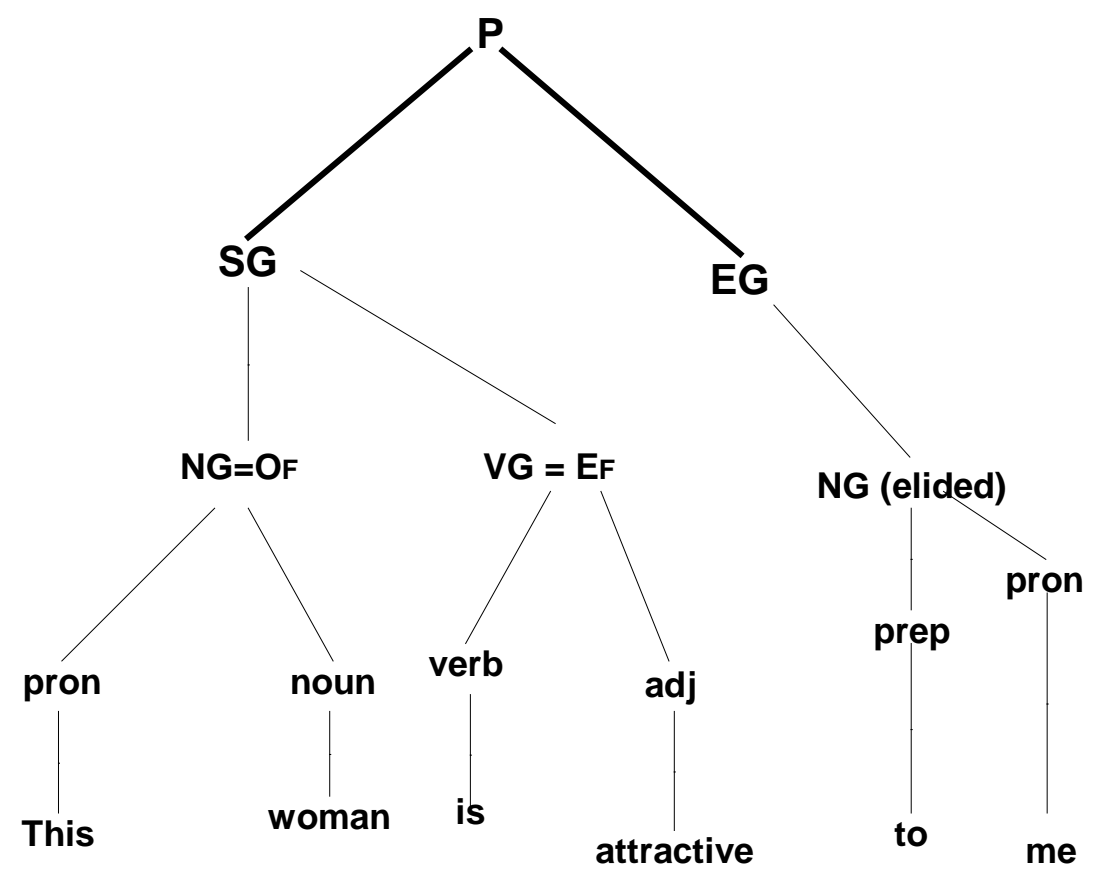

Figure 2: Tree diagram of mixed propositions.

Example 9: Suppose the proposition $\mathbf{P}$ "This is the face of a woman, with her flirtatious eyes, small nose, her mouth, her hair ... It's beautiful”. It shows clearly the tendency to make the estimation extensional and hence, to encompass to the maximum the whole of the perceptual field mentioned. In a diagram we have (Figure 3):

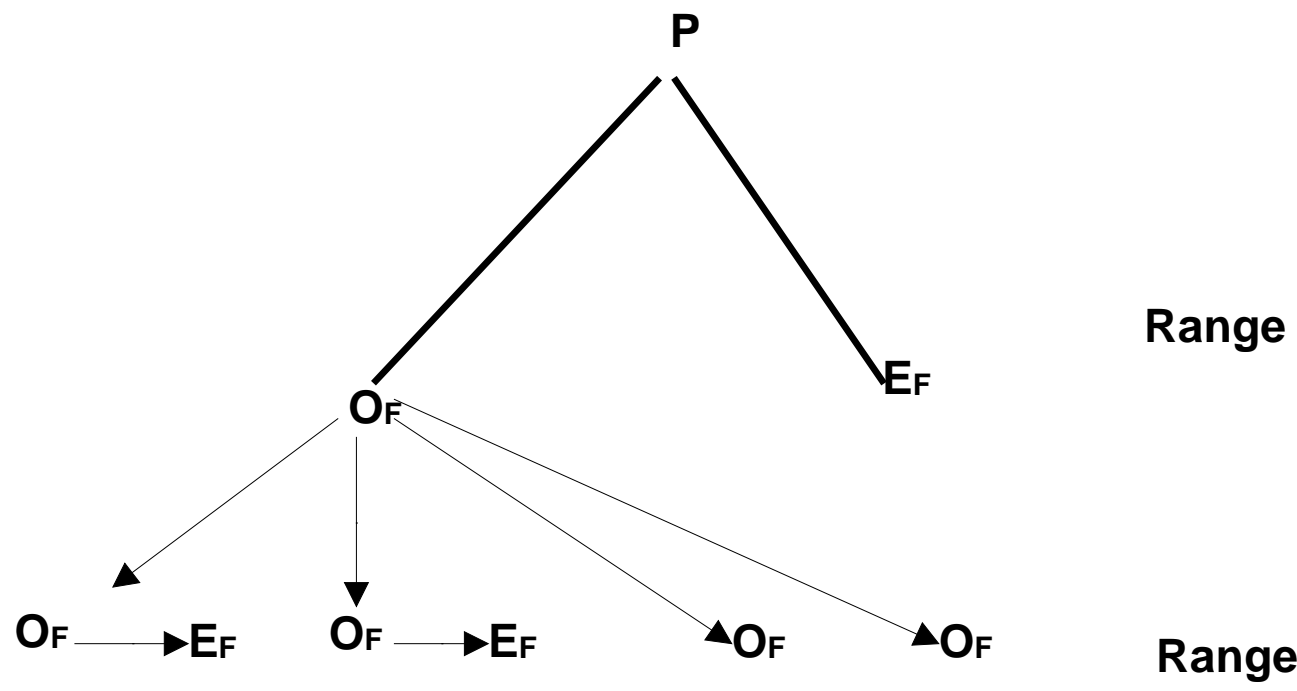

Figure 3: Diagram of ranges.

On the ratings of the first range we have:

$\mathrm{O}_{\mathrm{F}}=$ this is the face of a woman

$\mathrm{E}_{\mathrm{F}}=$ It's beautiful 
In the second range we have:

$$
\begin{aligned}
& \mathrm{O}_{\mathrm{F}}=\text { eyes } ; \mathrm{E}_{\mathrm{F}}=\text { flirtatious } \\
& \mathrm{O}_{\mathrm{F}}=\text { nose } ; \mathrm{E}_{\mathrm{F}}=\text { small } \\
& \mathrm{O}_{\mathrm{F}}=\text { mouth } \\
& \mathrm{O}_{\mathrm{F}}=\text { hair }
\end{aligned}
$$

Hypothesis 2: The process of communication of information requires understanding the message, supplied via a certain code, superimposed on the understanding of the sender, which the message expresses.

Thus, the transmission of information is not simply from message to message, not even sent message to understood message, but subject to subject. What the sender sends to the receiver is a significant that simultaneously emits linguistic signs (Morris, 1946). Every proposition cannot be conceived simply as predicate subject, but as an act of personalization, as the sender's personal proposal. For an entire sentence to be informative, it must be presented as expressive of a way of being and of understanding reality by the sender, precisely because the optional double character of communication having, on one hand, the sector of reality that is apprehended and on the other, the form and content of the message. Therefore:

Definition 5: The significance of a linguistic sign is the joined result of the subjective judgment, by the sender, of absolute being (referent) and subjective appreciation for the receiver, from the viewpoint of the subject of the transmitted information.

A linguistic sign has meaning when sent while there is a relationship between the denotative significance and the absolute being which is denoted, and the receiver understands what is communicated (Quine, 1960). When this coincidence does not emerge, no communication exists and the ambiguity appears which sender and receiver confer different connotative significance to the same denotative significance.

For Quine (1960) there is a category of lexemes, and in general terms, units of significance (moneme on) which play an ostensive function. These lexemes would be the extension of demonstrative pronouns "this", "that", etc.

Definition 6: We call ostensive those lexemes that function as verbal pointersto references external to the sender that may be real or unreal.

These minimal units of significance require an address to a reference that the sender locates outside himself.

In our theory we will divide propositions into ostentives and estimatives.

Definition 7: An ostensive proposition (O) is one in which the sender specifies connotations that apply to the reference, i.e., the nature of the qualitative and quantitative apprehension of reality that at that moment constitutes a referent.

Example 10: A proposition $\mathbf{P}=$ the book is on the table, is an ostensive proposition.

Definition 8: An estimative proposition (E) is one which plays an ostensive role not with respect to the referent, but to the sender. 
Example 11: A proposition $\mathbf{P}=I$ think Bach the best musician, is an estimative proposition.

\section{REFLECTIONS}

Language is relative as well. How can we speak about absolute being, then? We can and we cannot. Not being able to speak about absolute being completely is not a reason to stop speaking about it (Wittgenstein, 1972), because we can incompletely represent its completeness. Otherwise we would not be able to speak about anything, because languages are incomplete in their descriptions. Language is used inside a context, and depending of this context language will be different.

We have sought to answer in this paper some of the questions suggested by reviewers. Firstly, we do not know exactly if reality is one or is fragmented, because we are part of the same reality, although the idea of different spheres of experience, of-which we have discussed in the first section, suggests that this is a useful way to consider it.

Secondly, the world of events and entities are considered measured terms rather than phenomenological realities. To fulfill its function (linguistics), the names and terms should be syntactic fixed like all the other units of measurement and comparison. But their use is so successful that the danger of confusing these terms of measurement and comparison (model) with the measured world is to confuse convention with ontology, and to reduce the rich reality to the model. Linguistic structures, with which we form judgments or propositions do not allow a transitive verb without a subject or predicate. When there is "knowledge" the grammatical convention requires the existence of the knower and that which is known. Man is so used to it that when we talk and think and build our models, he does not realize that it is just that, a convention, and that the model does not correspond to the actual experience of knowledge. The fire of knowledge itself risks being quenched by the ashes of ignorance. Linguistic structures themselves impede the full apprehension of Reality $\mathbf{\aleph}$.

Just being aware of it, just knowing our limits, we can begin to catch a glimpse of the Reality $\boldsymbol{s}$ that is being continually denied. And this the only way we will achieve a basic principle of knowledge, which is so forgotten - humility.

\section{REFERENCES}

Agazzi, E. 1992.Some Philosophical Implications of Gödel's Theorem.In: Kurt Gödel Actes du Colloque, Neuchâtel, 13-14 juin 1991. (Ed. Denis Miévill). Travaux de Logique, 7. 129-159.

Black, M. 1968. The Labyrinth of Language.Praeger. New York

Bühler, K. 2011. Theory of Language: The Representational Function of Language.John Benjamins Publishing.

Carnap, R. 1942.Introduction to Semantics. Cambridge. Mass.

Cassirer, E. Philosophie der symbolischen Formen.(1. Die Sprache, 1923; 2.Das mythische Denken, 1925; 3. Phänomenologie der Erkenntnis, 1929). 
De Ajuriaguerra J., Bresson F. , Fraisse P. , Inhelder B. , Oléron P. , Piaget J.1963. Problèmes de psycho-linguistique. Presses Universitaires de France, Paris , (In French).

Freud, S. 2010. The Interpretation of Dreams. The Illustrated Edition.Sterling Press.

Gershenson, C. 2001.Comments to Neutrosophy.Proceedings of the First International Conference on Neutrosophy, Neutrosophic Logic, Set, Probability and Statistics, University of New Mexico, Gallup, December 1-3.

Gershenson, C. and Fernández, N. 2012. Complexity and information: Measuring emergence, self-organization, and homeostasis at multiple scales. Complexity. Vol 18. No 2. 29-44.

Lepschy, G.E. 1964. La lingüistique structural. Payot. Paris. (In French).

LeShan, L. and Margenau, H. 1982. Einstein's Space and Van Gogh’s Sky. MacMillan Publ. Co. Inc. New York.

Lyons, J. 1981. Language and Linguistics.Cambridge University Press.

Maddy, P. 1990.Realism in Mathematics. Clarendon Press. Oxford.

Maddy, P. 1996.Set theoretic naturalism.Journal of Symbolic Logic, 61.490-514.

Marx, K. 1998. "The German Ideology". Literary Theory: An Anthology. 2nd ed. Oxford: Blackwell.

Meinong, A. 1904. Über Gegenstandtheorie. Leipzig. J.A. Barth.. (In German)

Morowitz, H. 2012. The Plural of "Ontology" is "Confusion”. Complexity.Vol. 17. No 6. 5-6.

Morris, Ch. 1946. Signs, Language and Behavior.Prentice Hall. New York.

Nescolarde-Selva, J. and Usó-Domènech, J.L. 2013 ${ }^{\mathrm{a}}$. Semiotic Vision of Ideologies.Foundations of Science.DOI 10.1007/s10699-013-9329-9.

Nescolarde-Selva, J. and Usó-Doménech, J. 2013 ${ }^{\mathrm{b}}$ Reality, System and Impure Systems.Foundations of Science. DOI: 10.1007/s10699-013-9337-8.

Ogden, C.K. and Richard, I.A. 1989, The Meaning of Meaning. With a new introduction by Umberto Eco.Harcourt Brace Jovanovich, Publishers, Orlando. Florida.

Quine, W van O. 1960. Word and Object. MIT Press.

Russell, B. 1984.El conocimiento humano.Trans: Nestor Míguez. Orbis-Hyspamérica. España. (In Spanish). 
Sabán, M.J. 2012. Maasé Bereshit. El Misterio de la Creación. Buenos Aires. (In Spanish).

Schaff, A .1962. Introductionto Semantics. Pergamon Press. Oxford. New York.

Sebag, L. 1964. Marxisme et structuralisme. Editions Payot. Paris. (In French).

Tarski. A. 1956. Logic, Semantics, Methamathematics.Oxford.

Usó-Doménech, J.L. and Nescolarde-Selva, J. 2012.Mathematic and semiotic theory of ideological systems.Editorial LAP.Saarbrücken. Germany.

Wittgenstein, L. 1972. Tractatus Logico-Philosophicus. Routledge\&Kegan Paul. London. 